Operative Surgery-'Eyes, Ear, Nose and Throat' Consultant Editors: SiR STEWART DUKe-Elder and Maxwell Ellis. General Editors: Charles Rob and RoDNey SMITH. Second edition. Pp. 340, illustrated. London: Butterworths, 1969. $£ 8$.

This internationally known textbook of operative surgery was originally published in eight volumes between 1956 and 1958. The second edition is now available in 14 volumes.

The section dealing with Eye, Ear, Nose and Throat Surgery is edited by Sir Stewart Duke-Elder, President of the Institute of Ophthalmology, and Mr Maxwell Ellis, Dean of the Institute of Laryngology and Otology.

The list of contributors shows that surgeons with vast practical experience in particular operative techniques, working in many different centres in the United Kingdom and America, have combined to produce an authoritative textbook which should be available in all hospitals where this type of surgery is performed. The text is clear and concise with abundant simple, but excellent, illustrations.

This second edition of the ophthalmology section includes a considerable number of new techniques which have been perfected during the last 10 years.

Mr Maxwell Ellis states in his introduction to the Ear, Nose and Throat section that no outstanding alterations of technique have occurred since publication of the first edition but extensions of existing 'methods has meant revision of many chapters. An addition in this volume is an account of the trans-temporal bone approach to eighth nerve tumours by Dr William House of the University of South California.

This second edition fulfils admirably the original concept of Charles Rob and Rodney Smith of producing an outstanding and authoritative work covering all aspects of operative surgery.

\section{Modern Trends in Cardiac Surgery-2}

Edited by A.- H. Wooler and E. Aberdeen. Pp. 248, illustrated. London: Butterworths, 1968. $£ 35$ s.

This book comprises a series of articles on recent advances in heart surgery. Each one is written by an expert, is well illustrated, is largely concerned with operative technique and is accompanied by a good bibliography.

The opening chapter is by Morrow on the surgery of the aortic valve and outflow tract of the left ventricle (it is a pity that homografts are not mentioned). This is followed by two chapters on mitral valve disease, in which Wooler \& McMillan discuss the replacement of the mitral valve by a prosthesis, together with the use of the technique of annular plication, whilst Ionescu describes the use of aortic valve heterografts in the mitral position.

A most valuable and beautifully illustrated chapter by Gerbode \& Aberg on the anatomy of the conducting system of the heart is followed by an article by Shumacker on aneurysms of the ascending aorta and aortic arch, including dissecting aneurysms. Recent work on the hypotensive treatment of these latter aneurysms is described. The remarkable advances in the cardiac surgery of infancy are well documented by Aberdeen \& Carr, who describe the results of treating 3784 , cases of patent ductus, 295 cases of coarctation of the aorta, and 458 cases of systemic-pulmonary anastomosis. A description of the Waterston operation (anastomosis of ascending aorta to right pulmonary artery) could have been usefully included. A separate chapter on transposition summarizes well the management of this difficult problem.

The final two chapters are by no means the least important. Barnard provides a scholarly review of endocardial cushion defects and the accompanying illustrations help to clarify this difficult subject, whilst Bentall describes clearly the anatomy, haemodynamics and treatment of double outlet right ventricle.
This well-produced book is very good value considering its highly specialized nature, and is a 'must' for any cardiac surgeon.

\section{Intra-Thoracic Crises}

By A. L. D'Abreu, A. B. Taylor and D. B. Clarke. Pp. 334, illustrated. London: Butterworths, 1968. $£ 4$ 5s.

This interesting book, written by two surgeons and a physician from the University of Birmingham, is a successful attempt to describe the diagnosis and treatment of thoracic emergencies, many of which used to be regarded as hopeless or rapidly fatal but may now be treated satisfactorily providing an accurate diagnosis is made in time. The book covers much material which is difficult to extract from the standard textbooks and represents an original approach to this subject.

The book is divided into four parts. Part one covers the significance of the various symptoms referable to the chest. Parts two and three deal with the broad management of pulmonary, oesophageal and cardiac emergencies, whilst part four describes in detail the procedures enumerated in parts two and three. This division inevitably leads to some duplication of material (the detailed treatment of ventricular fibrillation is described in Chapter 10 and again in Chapter 15 ), and also some difficulty in obtaining complete information on a given subject. This could be a handicap for someone requiring rapid guidance for the treatment of an emergency.

The general presentation is acceptable and the book is well illustrated, though the clarity of some of the radiographs could be improved.

Part four is extremely good. It describes in great detail and illustrates clearly the maintenance of an adequate airway, bronchoscopy and oesophagoscopy, management of respiratory failure, tracheostomy, management of pulmonary embolus, chest aspiration and intercostal tube insertion, treatment of rib fractures and the management of cardiac arrest. For this section alone, the book well deserves a place in every hospital library. Part one, on the other hand, contains some interesting turns of phrase (e.g. p. 39 'the investigation of a suspected oesophageal foreign body requires plain radiology of the ingested foreign body in radio-opaques') and numerous paragraphs which make one wonder whether this section has been subiected to any editorial revision at all (e.g. p. 45 , paragraph 2 ; p. 51 , last paragraph; p. 54 , paragraph 3).

The book will prove invaluable to all hospital residents who have to deal with thoracic emergencies. 